\title{
The Impact of State and Trait Anxiety on Performance in a Source Monitoring Task
}

Kristina M. Kania

West Virginia University

Follow this and additional works at: https://researchrepository.wvu.edu/etd

\section{Recommended Citation}

Kania, Kristina M., "The Impact of State and Trait Anxiety on Performance in a Source Monitoring Task" (2011). Graduate Theses, Dissertations, and Problem Reports. 4738.

https://researchrepository.wvu.edu/etd/4738

This Thesis is protected by copyright and/or related rights. It has been brought to you by the The Research Repository @ WVU with permission from the rights-holder(s). You are free to use this Thesis in any way that is permitted by the copyright and related rights legislation that applies to your use. For other uses you must obtain permission from the rights-holder(s) directly, unless additional rights are indicated by a Creative Commons license in the record and/ or on the work itself. This Thesis has been accepted for inclusion in WVU Graduate Theses, Dissertations, and Problem Reports collection by an authorized administrator of The Research Repository @ WVU. For more information, please contact researchrepository@mail.wvu.edu. 
The Impact of State and Trait Anxiety on Performance in a Source Monitoring Task

Kristina M. Kania, B.A.

Thesis submitted to the

Eberly College of Arts and Sciences

at West Virginia University

in partial fulfillment of the requirements

for the degree of

Master of Science

in

Psychology

\author{
Elisa Krackow, Ph.D., Chair \\ Julie Patrick, Ph.D. \\ Constance Toffle, Ph.D. \\ Department of Psychology \\ Morgantown, West Virginia \\ 2011
}

Keywords: State Anxiety; Trait Anxiety; Source Monitoring; Memory 


\section{ABSTRACT \\ The Impact of State and Trait Anxiety on Performance in a Source Monitoring Task Kristina M. Kania}

This study examined the impact of state anxiety (current emotional state) and trait anxiety (predisposition) on a source monitoring task. The unique question asked in this study was whether highly anxious people who are distressed following a stressful to-be-remembered event are better at source monitoring. Seventy-two undergraduates completed a measure of anxiety and then either received an anxious mood $(n=36)$ or mood stabilizing $(n=36)$ induction before viewing to-be-source monitored material. Participants then completed a source identification task in which they were asked to identify the source of the to-be-source monitored information. Participants high in state anxiety were more accurate on the source identification task. The main effect of trait anxiety and the state-trait anxiety interaction were nonsignificant. Neither state nor trait anxiety impacted accuracy on misleading information items presented within the source identification task. 


\section{Acknowledgements}

There are many individuals I would like to thank for their support, time, and encouragement throughout this research project. First, I would like to thank Dr. Elisa Krackow, my academic advisor and thesis chair. Her continuous guidance, motivation, support, unending patience and availability during this project will always be remembered and reatly appreciated. I would also like to thank Dr. Julie Patrick and Dr. Constance Toffle for serving as members of my committee and for their time and invaluable feedback. I am grateful to Emily Cobun, Colin Jones, Hellen Nditsi, Kait Scott, Ria Travers, and Carman Vigliotti for their many hours of assistance with this project. Additionally, I am appreciative of the unconditional love, support, and encouragement from my parents during the completion of this project. 


\section{TABLE OF CONTENTS}

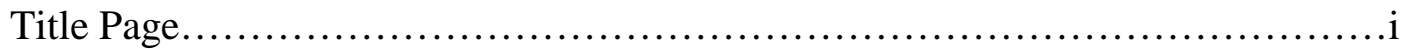

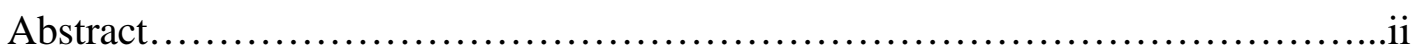

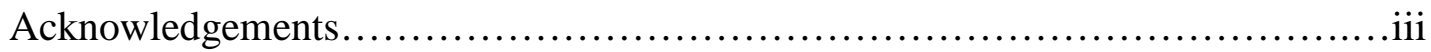

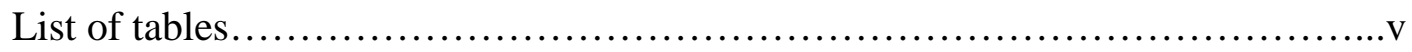

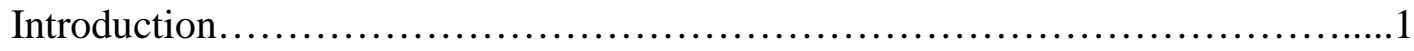

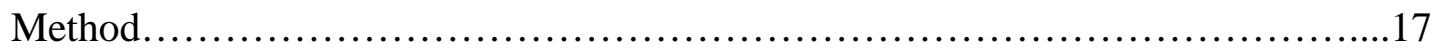

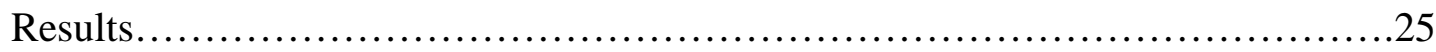

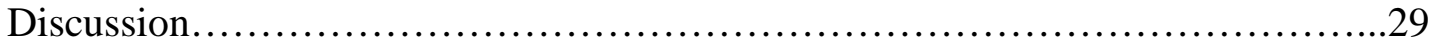

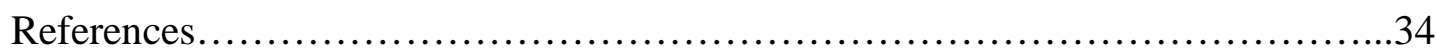

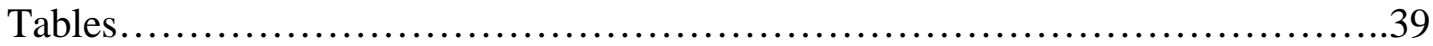

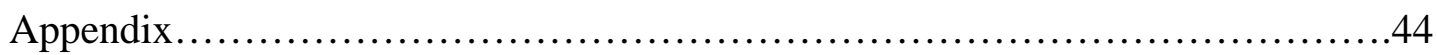




\section{LIST OF TABLES}

Table 1. Mean Anxiety Ratings on the Emotional Experiences Questionnaire Across

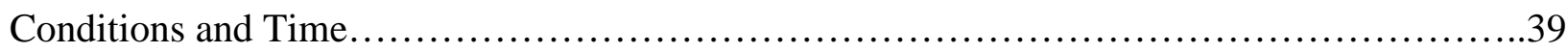

Table 2. Descriptive Statistics for Main and Interaction Effects on Total Correct Source

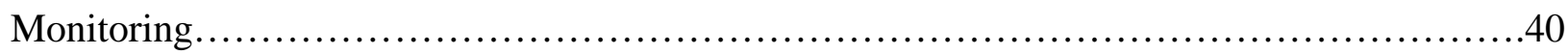

Table 3. Descriptive Statistics for Source Monitoring Question Type..........................41 
The Impact of State and Trait Anxiety on Performance in a Source Monitoring Task

\section{Anxiety and Memory}

People are often victims or witnesses to criminal activity. Understanding the factors that impact accurate reports of crime-related events is therefore important. A large body of research exists on memory for emotional events (see Reisburg \& Heuer, 2007, for a review). However, little research has examined how people with anxiety remember stressful events. In the real world, people are likely to become anxious when witnessing a crime. Therefore, it is important to determine whether people high and low in anxiety would remember the crime similarly. This research question motivated the proposed study. In the current study, the anxious mood induction will occur prior to the to-be-remembered event. This is considered to be advantageous over having a stressful event as the to-be-remembered event because memory for portions of the to-be-remembered event before and after people recognize the stressful nature of the event may be impacted differently.

Researchers have theorized that anxiety will impact memory (See Becker, Roth, Andrich, \& Margraf, 1999; Wenzel \& Holt, 2002). More specifically, people with anxiety are theorized to attend to threatening information due to the existence of hypothesized danger-related schemata, which guide their attentional processes when the schemata are activated (Beck \& Emery, 1979). Therefore, people with anxiety are expected to show better memory for threatening information or information that activates their anxiety than people without anxiety (See McCabe, 1999). That is, anxious individuals are expected to show a memory bias (i.e., superior memory) for anxiety-related information compared to nonanxious individuals. Attention to threat-related information is more likely to occur during physiological arousal (See Coles, Turk, \& Heimberg, 2007). 
Other researchers theorize relations between anxiety and cognitive processes which including memory. According to Eysenck and Calvo’s (1992) processing efficiency theory, processing efficiency is deficient in people with high anxiety due to their resources being utilized towards worry rather than towards the task at hand. Highly anxious people have been shown to increase their effort towards a task in order to prevent problems they foresee probably happening. Along with this, worry increases motivation, which leads to greater performance (Eysenck \& Calvo, 1992).

Empirical studies support the theory that people with anxiety disorders display memory biases for threatening information. For example, in a study examining memory biases in panic disordered individuals, Becker, Roth, Andrich, and Margraf (1999) found that, compared to the control participants, the panic disordered participants displayed a memory bias for panic disorder-relevant words. That is, panic disordered participants remembered more words associated with bodily symptoms (i.e., palpitations, constriction) than did control participants; however, both groups remembered neutral and positive words equally, ruling out a general bias toward emotional words.

Different types of anxiety disorders, including social anxiety disorder, have been studied in relation to memory biases. Individuals with social anxiety have also been shown to exhibit memory biases for negative information about oneself, possibly due to their fear of evaluation from others. Selectively remembering negative information about oneself may be connected to negative self-evaluations and a lack of self-reinforcement for social interactions, which could maintain a person’s anxiety about social situations (O’Banion \& Arkowitz, 1977). In this study, researchers asked women who were high in social anxiety and women who were low in social anxiety to interact individually with a confederate. They then received positive or negative 
feedback in the form of descriptions about how the confederate felt about them. O’Banion and Arkowitz (1977) hypothesized that women who were given positive descriptions from the confederate would recall more positive information about themselves than the women who were given negative descriptions. The results showed that women who were rated high in social anxiety remembered negative descriptions of themselves better than did women who were rated low in social anxiety. The two groups did not differ on their memory of positive selfdescriptions, demonstrating that social anxiety may be mediated and maintained by this selective memory for negative information about oneself (O’Banion \& Arkowitz, 1977).

In a second study that examined memory biases in people with social anxiety, Wenzel and Holt (2002) provided socially anxious individuals and non-anxious control individuals with written stimuli with evaluative threat-related words and neutral words. Their results, in support of their hypotheses, showed that the socially anxious participants remembered more of the evaluative threat material than the neutral material and recalled more threat-related words than the non-anxious control participants (Wenzel \& Holt, 2002).

People with Generalized Anxiety Disorder also are expected to exhibit memory biases. Coles and colleagues (2007) conducted the first study on memory biases in persons with Generalized Anxiety Disorder using personally-relevant threatening words. Participants were diagnosed with Generalized Anxiety Disorder based on the Anxiety Disorders Interview Schedule for DSM-IV: Lifetime Version. Control participants did not meet criteria for any current or past Axis I disorders. Participants were given a list of 80 words: 40 Generalized Anxiety Disorder-related threat words, 20 neutral words, and 20 GAD-related positive words. They rated each word on a Likert-scale ranging from $-3=$ "extremely negative for me” to $+3=$ “extremely positive for me.” The words to be remembered were chosen for each participant 
based on his/her ratings to ensure relevance for each participant. The participants completed an incidental learning task, which means that the participants were not aware that they would be tested on their memory for the material at a later point. The task required participants to view words they previously rated as threatening, neutral, and positive; to imagine themselves in a situation involving each word; and then to rate how easy or difficult it was to imagine the scene. The participants then completed a 5-minute non-verbal filler task, which had them complete patterns presented to them visually. Next, the participants completed a stem-completion task to measure implicit memory. The task required participants to look at the first three letters of a word and complete the word with the first letters that came to mind. Finally, the participants completed a free recall task that required them to write down as many words as they could remember from the incidental learning task. The researchers found that participants with Generalized Anxiety Disorder remembered more threatening words, demonstrating a memory bias, and rated the threatening words as being more negative than did the nonanxious controls (Coles et al., 2007).

Evidence of a memory bias in anxious individuals may depend on the extent to which a person is high or low in trait anxiety. Specifically, McCabe (1999) wanted to determine if selective memory for threat, as is shown in panic-disordered patients, only occurs after an unexpected panic attack or if it is related to the anxiety sensitivity level of the individual and whether it is more pronounced when arousal is high. She examined memory biases in people with high trait anxiety and in people with low-trait anxiety, as measured by the Anxiety Sensitivity Index, specifically focusing on selective memory for anxiety-related words (e.g., palpitation, fearful) and general threat words (e.g., explosion, poison). The design of this study included positive words (e.g., optimistic, pleasant) to control for a bias in emotional words. 
Neutral words (e.g., oven, bench) were also included to serve as a baseline measure of memory. Participants were first randomly assigned to the high-arousal and low-arousal conditions. They were then shown words and asked to rate the extent to which they liked or disliked the word on a 7-point Likert scale, ranging from -3 (strongly dislike) to +3 (strongly like). Six neutral words were included to control for primacy and recency effects and the remainder of the words included 24 positive words, 24 neutral words, 24 anxiety-related, and 24 general threat words. The participants in the high-arousal condition then participated in a hyperventilation task and the participants in the low-arousal condition participated in a relaxation task. Participants in both groups then completed measures evaluating their anxiety levels. Following this, participants completed a word stem completion task to measure implicit memory. Next, they completed a cued recall test to measure explicit memory. Finally, participants completed measures, including the ASI (McCabe, 1999).

McCabe (1999) used a 2 (Group: High Anxiety, Low Anxiety) X 2 (Arousal: High Arousal, Low Arousal) ANOVA. The results indicate a memory bias in people with high trait anxiety for general threat words, but not for anxiety-related words. People with high trait anxiety also evaluated the words to be significantly more negative than did people with low trait anxiety. People with low trait anxiety remembered more positive words, suggesting that they attend to positive information more than people with high trait anxiety. Greater attention to positive stimuli is thought to be a protective factor preventing people from developing anxiety. Although analyses revealed that the arousal manipulation was successful, arousal level did not impact memory performance. There was no effect of state anxiety on memory (McCabe, 1999). 
Additional studies have examined the impact of anxiety on memory for nonthreatening stimulus materials. Kaye, Kirschner, and Mandler (1953) examined the effect of test anxiety in adults, as measured by an anxiety questionnaire designed to specifically measure test anxiety (See Sarason \& Mandler, 1952), on memory for number series, mixed letter and number series, and short word series in a group testing situation. Participants were split into high- and lowanxiety groups and told that they were going to take the working memory portion of the IQ test and receive their scores shortly afterward. The low-anxiety participants scored higher on the test than did the high-anxiety participants.

\section{State Anxiety Induction}

Anxiety induction has been utilized in studies examining an individual's accuracy on an eyewitness task to observe the differential effects of anxiety levels on eyewitness memory. Dobson and Markham (1992) induced anxiety in 120 undergraduate psychology students using evaluative threat to increase state anxiety at encoding, at retrieval, at both encoding and retrieval, or at neither point. They hypothesized that participants who were in a high state of anxiety at both encoding and retrieval would be less accurate on an eyewitness task than would lowanxious participants. They also hypothesized that inducing evaluative threat during their state anxiety induction during retrieval would decrease the high-anxious participants’ accuracy, but would not negatively impact low-anxious participants’ accuracy. Participants were told they were going to view some slides that they would later be asked about. State anxiety was induced via telling the participants in two high anxiety groups and two low anxiety groups that their performance on the task was directly related to intelligence; highly correlated with their academic success; and their performance would be compared to their peers' performances. First, participants viewed slides showing an incident of purse-grabbing and the events that occurred 
before and after that incident. Second, participants completed a questionnaire for 20 minutes regarding their opinions about crime and punishment. The group that was assigned to experience the state anxiety induction only at encoding was then told that they were not going to be being evaluated during the following recognition task. Next, participants either received anxietyinducing instructions if they were in the experimental groups assigned to receive the state anxiety induction at retrieval or at both encoding and retrieval, or participants received control instructions. Finally, the participants answered 30 multiple-choice questions about the slides they viewed (Dobson \& Markham, 1992).

Dobson and Markham’s (1992) results, in support of their hypothesis, showed that lowanxious participants were more accurate on the eyewitness task than were the high-anxious participants when state anxiety was induced at both encoding and retrieval. The performance of the high-anxious participants and low-anxious participants did not differ significantly in the remaining three conditions. Low-anxious participants were more accurate on the eyewitness task when they experienced the state anxiety induction at encoding and retrieval than they did in the control condition. High-anxious participants did not differ significantly on their memory accuracy in the state anxiety induction condition from in the control condition. Furthermore, their findings support the idea that the interaction of individual and situational variables plays an important role on eyewitness accuracy (Dobson \& Markham, 1992).

In sum, the previously described studies show that higher levels of anxiety are associated with lower levels of recall.

\section{Anxiety and Suggestibility}


Research shows that memory and suggestibility are related. The memory trace strength theory of suggestibility states that stronger memories are more resistant to suggestibility. A memory will gain strength with greater exposure to an event or item (Pezdek \& Roe, 1995).

Ridley and Clifford (2004) examined the impact of state anxiety on suggestibility. They, like Dobson and Markham (1992), used evaluative threat to induce state anxiety, specifically at either encoding or retrieval of misleading post-event information, at both encoding and retrieval, or at neither point. First, the participants completed a visual analogue mood scale (VAMS) in order to measure state anxiety. Second, they viewed a 3-minute video depicting a kidnapping scenario. Third, participants completed a second VAMS to measure their state anxiety. Fourth, they were interviewed individually with either misleading content or with correctly leading content, without the knowledge that misleading post-event information might be included. Participants who were assigned to experience the state anxiety induction during encoding and during both encoding and retrieval were videotaped and watched themselves on a monitor. They were told that a mock-jury would evaluate their performance. After this, all participants completed another VAMS to evaluate state anxiety induction or to gather control data. Participants then completed irrelevant questionnaires to ensure that 15 minutes passed. At this point, participants who were assigned to experience the state anxiety induction at retrieval went through the same procedure as the other groups previously experienced. The participants assigned to experience the state anxiety induction at both encoding and retrieval went through the same procedure again at this point. Finally, all participants then answered a standard set of questions and then completed another VAMS (Ridley \& Clifford, 2004).

Ridley and Clifford (2004) found that the state anxiety induction was successful and, therefore, increased levels of anxiety for all participants. An ANOVA was conducted examining 
the anxiety groups separately and combined, but no significant main or interactions effects were found for memory accuracy. A significant main effect of anxiety on suggestibility in the misled condition was found. A t-test revealed that the participants in the misinformed condition who did not experience the state anxiety induction were significantly more suggestible than the other groups. Implementing a state anxiety induction during encoding, retrieval, or both encoding and retrieval significantly reduces suggestibility for people who have been misled. This suggests that state anxiety inductions have an impact on memory accuracy at encoding and/or retrieval when misleading post-event information is presented (Ridley \& Clifford, 2004).

Several studies have examined the question of whether anxiety impacts suggestibility in children. Ridley, Clifford, and Keogh (2002) hypothesized that children will be suggestible to misleading information. Supported by Eysenck and Calvo’s (1992) processing efficiency theory, they also predicted that high- and low-state-anxious children would not differ significantly on correctly leading information, but that they would differ in suggestibility levels on misleading information. The study design was a 2 (high or low state anxiety) X 2 (misleading or correctly leading) factorial. They also ran correlations among memory accuracy, suggestibility, state anxiety, and depression. Eighty-three children were tested in two separate classes at two separate schools. The classes were randomly assigned to one of the experimental groups manipulating misleading or correctly leading information. Children whose percentile rank of the sample for state anxiety was equal to or exceeding 66 were included in the high anxiety group and children whose percentile rank was equal to or less than 33 were in the low anxiety group. First, all of the children viewed a 3-minute, 45-second video of a car accident. Second, they answered questions about the video they viewed, which included misleading information for the misleading group or correctly leading information for the control group. They ensured that 10 
minutes passed between the second and third steps of the study during which time the children completed Spielberger’s State-Trait Anxiety Inventory for Children. Finally, the children answered questions that were meant to examine the effects of misleading information on their memories (Ridley et al., 2002).

Ridley et al. (2002) found that state anxiety did not significantly affect the accuracy of the participants' memory for correctly leading questions, but that state anxiety led to more accurate responses to misleading questions in the children. That is, children high in state anxiety were less suggestible.

Almerigogna, Ost, Bull, and Akehurst (2007) examined whether the combination of state and trait anxiety, as measured by the State-Trait Anxiety Inventory for Children (STAI-C), influences children's suggestibility to misleading information when the misleading information is presented during a memory interview in the form of misleading questions. First, children completed the STAI-C. Second, the children watched a movie clip from the children's film 'Madeline' in groups of 14-23 people. Next, the children were interviewed individually and were asked seven non-leading control questions and seven misleading questions about the film clip they viewed. The experimenters manipulated the interview style, hoping to impact state anxiety, by having children interviewed by either a supportive or a non-supportive interviewer. Immediately after the memory interview, children again completed the STAI-C. The nonsupportive interviewer condition was utilized to induce state anxiety in those children. A 2 (Interviewing Style: supportive or non-supportive) X 2 (Measures: memory accuracy and suggestibility) MANOVA was conducted. An effect was found for interviewing style and suggestibility scores, with children interviewed in the non-supportive condition providing significantly more inaccurate answers to misleading questions. There was no effect of 
interviewing style on memory accuracy scores. Next, effects of post-experimental anxiety on responses to correctly leading and misleading questions were examined. A 4 (Anxiety: high and low state anxiety and high and low trait anxiety) X 2 (Measures: accuracy, suggestibility) MANOVA was conducted. Children high in both state and trait anxiety gave more inaccurate answers to misleading questions than did children low in both state and trait anxiety. High-trait and high post-interview state anxiety did not significantly affect correct responses to correctly leading questions. In sum, the results of this study show that state anxiety decreases accurate responses to misleading questions. Trait anxiety negatively impacts responses to misleading questions. The combination of high state anxiety and high trait anxiety yields similar findings. With respect to misleading questions, state anxiety, trait anxiety, and the combination of state anxiety and trait anxiety do not impact the accuracy of responses to correctly leading questions (Almerigogna et al., 2007).

Much of the research on anxiety and suggestibility has utilized the Gudjonsson Suggestibility Scale (Merckelbach et al., 1998). The scale is purported to examine an individual's suggestibility. Suggestibility is defined in two ways. First, it is defined as susceptibility to being influenced by leading questions, known as "Yield." Second, suggestibility is defined as susceptibility to changing an answer under pressure, known as "Shift" (Merckelbach, Muris, Wessel, \& van Koppen, 1998). The GSS uses the following procedure: First, a narrative is read aloud to the participant. Second, the participant verbally recounts as much as he or she can remember about the passage. Third, the experimenter then asks the participant a standard set of questions that include misleading questions. Finally, the interviewer provides negative feedback by convincingly telling the participant that he or she inaccurately answered several of the questions and has the participant attempt to answer the entire set of 
questions for a final time. The examiner records any changes in the participants' answers. Changes in answers are referred to as “Shifts” (Merckelbach et al., 1998). The literature shows that not every person shifts their answers due to a wide variety of individual differences.

In one such study, Gudjonsson (1988) examined the effects of state anxiety on suggestibility. First, participants listened to the narrative for the GSS. Second, they completed the free recall portion of the GSS followed by the Spielberger State Anxiety Inventory (SAI) and several other questionnaire measures not pertinent to this proposed thesis project. Third, they provided recall for the narrative after the delay during which they were completing the scales. Next, participants completed the SAI again in reference to their emotions during the time they were participating in the GSS interrogation. Finally, they reported any coping skills they had utilized during the interrogation (Gudjonsson, 1988). Gudjonsson (1988) found that state anxiety is more closely related to suggestibility than is trait anxiety. This may be due to the fact that state anxiety, not trait anxiety, is influenced by the immediate context (e.g., interrogative process). Specifically, Yield 2 (after negative feedback) and Shift scores on the GSS correlate more strongly with anxiety than do initial scores on the misleading questions. This study found a moderately high significant correlation between state anxiety and suggestibility, particularly Yield 2 scores, increasing as state anxiety increased $(r=0.48)$. In regard to Shift scores, this correlation was strongest after the individuals with anxiety were given negative feedback $(r=$ 0.69). In sum, after receiving negative feedback, participants with anxiety are more likely to respond to misleading questions incorrectly and to change their answers to the questions (Gudjonsson, 1988). In other words, they are more suggestible.

To observe the relationship between state and trait anxiety and suggestibility, Wolfradt and Meyer (1998) conducted a study using the Gudjonsson Suggestibility Scale, in which 
participants with an anxiety disorder were compared to a nonanxious control group. First, the participants completed the GSS-2 to measure suggestibility. After the immediate recall of the narrative passage, participants completed the State Trait Anxiety Inventory. The delayed recall phase of the GSS-2 was not examined due to the investigators' concern of the clinical population overexerting themselves. The anxiety disordered participants, who endorsed high levels of state anxiety $\left(M_{\text {anxious }}=54.36, \mathrm{SD}=11.97\right.$ vs. $\left.M_{\text {control }}=26.78, \mathrm{SD}=2.50\right)$ and trait anxiety $\left(M_{\text {anxious }}=57.84, \mathrm{SD}=8.91\right.$ vs. $\left.M_{\text {control }}=27.38, \mathrm{SD}=3.30\right)$, were more suggestible on the GSS-2 factors of suggestibility Yield, Shift, and total suggestibility than were the control participants (Wolfradt \& Meyer, 1998).

In sum, across studies, anxious individuals in a high state of anxiety were more suggestible than were the nonanxious controls.

\section{Anxiety and Source Monitoring}

According to Johnson, Hashtroudi, and Lindsay (1993), source monitoring involves people making decisions about where they learned specific information, beliefs, and memories as they are attempting to recall them. The amount of information recalled and the degree to which a person feels confident in their recollections varies greatly from person to person and even within a person (i.e., remembering someone's face, but not how you know them, or remembering that you were given a piece of information, but cannot recall who gave it to you). The source monitoring hypothesis states that source monitoring errors occur when a misled person is asked to recall the source of their information and they mistakenly recall the details of the misleading information as the details of their experienced event. When a person bases his/her judgment about the source of their information on the fact that the information presented looks familiar, 
rather than basing his/her judgment on the cues presented about the specific details of the original event, that person is likely to make source monitoring errors (Johnson et al., 1993).

Johnson et al. (1993) report that an emotional event (i.e., an event that elevates a person’s state anxiety level) can disturb the encoding process, making it more difficult or impossible for a person to later recall certain specific details of the original event. Along with this, they also state that a person who is highly anxious at the time of recall may have more difficulty recalling the information from the original event, as this can disrupt their source monitoring. Therefore, individuals are more likely to recall be more accurate in source monitoring if they are not anxious at the time of recall.

Also concerned with source identification, Ridley and Clifford (2006) conducted a correlational study where they hypothesized that tasks that require an individual to recall the source of their memory (source attributions) would increase levels of worry in people with high trait anxiety, leading to increased effort to respond accurately, which would result in fewer source misattribution errors. According to Eysenck and Calvo’s (1992) processing efficiency theory, highly anxious people utilize increased effort to accurately complete a task, but it increases the length of time it takes them to complete the task. Fifty-four undergraduate students first viewed a 5-minute video showing a burglary and car chase. Second, they completed questionnaires containing misleading information. Third, the students completed the state and trait anxiety questionnaires. Next, they completed an irrelevant writing task to ensure that 15 minutes elapsed between the to-be-source monitored information and the source identification task. Finally, participants completed a source monitoring task for which they were instructed verbally and in writing that there were a few statements in the source identification task that were 
solely from the questions and that they should declare where they recalled learning of the items presented (Ridley \& Clifford, 2006).

Ridley and Clifford (2006) found that participants high in state anxiety made fewer source monitoring errors than participants lower in state anxiety. A multiple regression analysis was conducted that removed items for which people could not remember the source. The results of the analysis increased the amount of variance originally accounted for when the items for which people could not remember the source were included and increased the strength of the original correlation found between state anxiety and source misattribution errors. When these forgotten items were excluded, an even stronger positive relationship emerged between state anxiety and source misattribution errors. The relationship between trait anxiety and source misattribution errors was nonsignificant and the interaction between state and trait anxiety was nonsignificant (Ridley \& Clifford, 2006).

The literature varies on the relationship between source monitoring and anxiety. Studies have found different results on whether high anxiety increases or decreases source monitoring errors. This fact requires further research to be conducted in this area.

\section{The Current Study}

The current study examined whether people who are anxious versus nonanxious performed differently on an eyewitness task when in a state of high versus low anxiety. Only one previous study (Ridley \& Clifford, 2006) has examined whether state and trait anxiety impact eyewitness performance in adults, but the study asks a different research question than the current study by nature of the fact that the researchers measured state anxiety after the to-be-remembered event. The current study asked the question whether highly anxious people who are distressed following a stressful to-be-remembered event are better at source monitoring. In addition, in the 
previous study, the researchers did not manipulate state anxiety. As a result, the previous study is confounded by the typical high correlation between state and trait anxiety. Further, the previous study measured anxiety using the State-Trait Anxiety Inventory. The current study examined anxiety utilizing the Mood and Anxiety Symptom Questionnaire, as it is a measure of pure anxiety and has the ability to differentiate anxiety from depression (see Reidy \& Keogh, 1997; Keogh \& Reidy, 2000).

In the current study, 4 groups (high trait, high state; high trait, low state; low trait, high state; low trait, low state) were formed to represent various combinations of state and trait anxiety. This combination of groups enabled the researchers to answer the key question about whether anxiety impacts eyewitness performance when participants are in a high anxious state. Participants’ anxiety levels were measured using the Mood and Anxiety Symptom Questionnaire. Participants with high and low anxiety then experienced a high or low (i.e., mood maintenance) state anxiety manipulation. High state anxiety was induced via an anxious mood induction prior to presenting the to-be-remembered stimulus materials. Low state anxiety was maintained via a mood stabilizing induction. As in the Ridley and Clifford (2006) study, participants were presented with to-be-source monitored information via two methods: (1) viewing a forensically relevant video and (2) responding to questions designed for the purpose of presenting information to participants. Next, participants were given a positive mood induction and additional activities to ensure that the effects of the anxious mood induction no longer impacted participants when they next participated in a source monitoring task (see also Ridley \& Clifford, 2006 for this task).

The following hypotheses and research questions were addressed by the current study. 
H1: There will be a main effect of trait anxiety, but the direction of the effect will not be hypothesized.

H2: There will be a main effect of state anxiety. Based on Ridley and Clifford (2006), people high in state anxiety will make fewer errors on the source monitoring task.

RQ1: Will there be an interaction between trait and state anxiety?

\section{Method}

\section{Participants}

Participants were 98 West Virginia University undergraduate students. Of the original 98 participants, data from 14participants was excluded due to missing data and/or scores of 4 or higher on the Zuckerman-Kuhlman Personality Questionnaire: Infrequency validity items. An additional 12 participants' data were excluded from the analyses because the anxious mood induction was not effective in increasing their anxiety ratings by at least 1 point on the Emotional Experiences Questionnaire. Therefore, 72 participants were included in the analyses. Half of the sample $(n=36)$ was in the anxious mood induction condition, while the other half was in the mood stabilizing condition. The number of participants in each group was: high state anxiety, high trait anxiety $(n=5)$; high state anxiety, low trait anxiety $(n=31)$; low state anxiety, high trait anxiety $(n=13)$; and low state anxiety, low trait anxiety $(n=23)$. The majority of participants were female (79.2\%). Ages of participants ranged from 18 to 25 years $(M=20.07$, $S D=1.75)$.The majority of participants self-identified as non-Hispanic/Caucasian (88.9\%), 2.8\% as black/African American, $2.8 \%$ as biracial, $2.8 \%$ as other, $1.4 \%$ as Asian, and $1.4 \%$ as Hispanic/Latino. Broken down by year of college, 26.4\% were freshmen, 33.3\% were sophomores, $25 \%$ were juniors, and $15.3 \%$ were seniors. Participants were tested in groups of fewer than 8 individuals. If a single participant arrived at the session $(n=20)$, the participant was 
run individually. Steps were taken to ensure participant privacy during the procedure, including seating participants several seats away from other participants. Participants were recruited via West Virginia University’s Research Participation System (SONA), fliers, and in-class announcements.

\section{Measures}

Mood and Anxiety Symptom Questionnaire (Clark \& Watson, 1991).The Mood and Anxiety Symptom Questionnaire is a 90-item self-report questionnaire. The current study included 89 of the 90 questions. The question referring to suicidal ideation and behavior was omitted, due to the fact that research has shown that this question loads on the depression scale, rather than the anxiety scale.

The Mood and Anxiety Symptom Questionnaire consists of three major scales: General Distress, anxiety-specific (Anxious Arousal), and depression-specific (Anhedonic Depression). The three-factor structure is supported by several investigations of the factor structure (Watson et al., 1995a; Watson et al., 1995b; Reidy \& Keogh, 1997; Keogh \& Reidy, 2000). The General Distress scale is comprised of three subscales: depressive symptoms, anxious symptoms, and mixed anxiety-depressive symptoms. Each scale has strong internal consistency, ranging from 0.78 to 0.92 (Buckby, Yung, Cosgrave, \& Killackey, 2007). Watson et al. (1995a) examined the Mood and Anxiety Symptom Questionnaire and found that the measures of anxiety and depression exhibited high convergent validity, with anxious arousal correlating $r=.72$ on average with general distress: anxiety and with anhedonic depression correlating $r=.70$ on average with general distress: depression. They also found that the anxious arousal and anhedonic depression scales were strong markers of the constructs they purport to measure, with general distress: anxiety and general distress: depression sharing 48\% of their variance on 
average and with anxious arousal and anhedonic depression sharing only $12 \%$ of their variance on average.

Reidy and Keogh (1997) also examined the discriminant and convergent validity of the Mood and Anxiety Symptom Questionnaire and found that the anxious arousal and anhedonic depression scales were successfully able to discriminate between anxiety and depression and exhibited high convergent validity. Anxious arousal correlated strongly $(r=.75)$ with general distress: anxiety correlated. Anhedonic depression correlated strongly $(r=.73)$ with general distress: depression. Anxious arousal was correlated moderately $(r=.45)$ with anhedonic depression showing discriminant validity between anxiety and depression. The scales of the Mood and Anxiety Symptom Questionnaire appear to be able to discriminate nonclinical anxiety and depression better than scales of other measures (Keogh \& Reidy, 2000), such as the widely used State-Trait Anxiety Inventory.

The Mood and Anxiety Symptom Questionnaire was used to identify participants who were assigned to one of four conditions: high trait anxiety, high state anxiety; high trait anxiety, low state anxiety; low trait anxiety, high state anxiety; or low trait anxiety, low state anxiety. Participants who scored 27 or above on the General distress: anxious arousal scale $(n=16)$ or 25 or above on the General Distress: Anxiety sensitivity scale $(n=2)$ were assigned to the high trait anxiety conditions. The mean score on General Distress: Anxious Arousal scale for high trait anxiety participants was $M=34.72, S D=7.74$, range $27-52$ and was $M=22.04, S D=3.86$, range = 20-25 for low trait anxiety participants. The mean score on the General Distress: Anxiety Sensitivity Scale for high trait anxiety participants was $M=27.00, S D=4.31$, range $=20-34$ and was $M=17.65, S D=3.19$, range $11-25$ for low trait anxiety participants. This cut is based on means and standard deviations used in previous investigations. Further evidence for utilizing the 
selected Mood and Anxiety Symptom Questionnaire cut-off scores is found in the raw data from Wu and Watson (2005). This data set contains Mood and Anxiety Symptom Questionnaire general distress: anxiety scores for an outpatient sample diagnosed with anxiety disorders (i.e., obsessive compulsive disorder).

Demographic questionnaire. This questionnaire included questions regarding participants' sex, ethnicity, year in college and family income. The questionnaire also included questions about whether participants had been diagnosed with learning disabilities, Attention Deficit/Hyperactivity Disorder (ADHD) and are currently in treatment or have had past treatment for an anxiety disorder. Participants who had been diagnosed with an anxiety disorder and/or had previous or current treatment for anxiety were assigned to the low state anxiety condition.

\section{Zuckerman-Kuhlman Personality Questionnaire: Infrequency validity items}

(Zuckerman, 2002). There are 10 infrequency validity items on the Zuckerman-Kuhlman Personality Questionnaire. Inclusion of these items allowed the researchers to identify those participants who were attempting to present in a socially desirable manner and/or those who were possibly answering the items haphazardly. Each item endorsed is scored as one point. Data from participants scoring at least five points on these items were not used in this study due to a possible invalid response style.

Emotional Experiences Questionnaire (Roisman, Fortuna, \& Holland, 2006). This questionnaire asks participants to rate the strength of 25 positive and negative emotions they may be experiencing. The emotions being rated include a range of emotions, such as anxiety, amusement, happiness, and shame, in order to prevent participants from unmasking the researchers' intention to manipulate ratings of state anxiety. Participants rated their emotions on a 9-point Likert scale from 0 (Not at all) to 8 (The most in my life). This questionnaire was 
given before and after the anxious mood and mood stabilizing inductions to allow the researchers to be able to determine if the inductions were effective. This questionnaire was also given before the source identification task as a way to check that participants were no longer in a high state on anxiety while completing the source identification task.

It was expected that participants who received the anxious mood induction would increase their anxiety rating after the anxious mood induction. For the participants who received the mood stabilizing induction, it was expected that their pre-post anxiety ratings would not change significantly.

Mood inductions. The participants experienced either an anxious mood induction or a mood stabilizing induction. The current study induced state anxiety following the procedures used by Sinclair, Soldat, and Ryan (1997). This induction procedure was used because it led to observable changes in the participants' anxiety levels in multiple studies and because other anxious mood inductions confound increasing anxiety with the to-be-remembered information.

Anxious mood induction (Sinclair, Soldat, \& Ryan, 1997, Study 2). The participants were given a booklet composed of 59 sheets of paper with one statement typed on a sheet. The 59 statements included were designed to induce anxiety. The participants also received a CD with the 59 statements read to them at the rate of one per 15 seconds. They were to follow along in the booklet as they heard the statements read to them on the CD. The CD told participants that “These statements are designed to make you feel anxious” (Sinclair et al., 1997, p. 168). The statements started off neutral (“Today is neither better nor worse than any other day.” Sinclair et al., 1997; p. 171) and became increasingly more anxiety related ("I feel paralyzed with fearsome very important decisions are almost impossible to make.” Sinclair et al., 1997; p. 173). One of the 60 statements in the induction was removed because it appeared very early in the sequence 
and was not a neutral item. When the participants reached the end of the booklet, they were told on the CD, “Now that you're feeling very anxious, concentrate on this feeling. Feel it getting stronger and stronger, more and more worried. Let it continue to build...Do and think whatever you can to build this very anxious mood. Feel very, very anxious. Close your eyes. Begin now” (Sinclair et al., 1997, p. 168, 173). After two minutes of focusing on increasing the feeling of anxiety, participants again completed the Emotional Experiences Questionnaire. This induction procedure was used because it led to observable changes in the participants' anxiety levels in multiple studies (Sinclair et al., 1997).

Mood stabilizing induction. The mood stabilizing induction was based upon the mood induction used in Josephson, Singer, and Salovey (1996) and as such featured a video segment of This Old House, which is a home-improvement show. The segment was the same length as the anxious mood induction procedure.

Presentation of the to-be-source monitored information. Participants received information from two sources_-a video and a questionnaire. Participants viewed a 5-minute portion of a crime video depicting a burglary and a car chase that was used by Chambers and Zaragoza (2001) and Mitchell, Johnson, and Mather (2003). Later, participants were given a 36item questionnaire (Mitchell et al., 2003) that consists of 3 sections of 12 questions each to allow participants to review the 12 event components in the video a total of 3 times. Chambers and Zaragoza (2001) showed that being exposed to misleading information multiple times enhances the number of source monitoring errors.

Positive mood induction. All participants experienced a positive mood induction in order to ensure that participants in the high state anxiety conditions were no longer in a state of high anxiety while they were completing the source identification task. The induction required 
that the participants listen to classical music for approximately 30 minutes. This induction has previously been shown to effectively induce a positive mood (Roisman, Fortuna, \& Holland, 2006).

Filler tasks. Participants engaged in filler tasks for approximately 10 minutes (i.e., word search) after viewing the to-be-source monitored video. The anxious mood induction has been shown to last approximately 35 minutes (Sinclair, Soldat, \& Ryan, 1997). Therefore, it was necessary to ensure that approximately 40 minutes had passed from the end of the anxious mood induction until the time of the Source Identification Questionnaire, in order to be certain that participants were no longer in a state of high anxiety when they completed the source identification task. The positive mood induction described above took approximately 30 minutes, thereby necessitating this second 10-minute filler task before the source identification task.

Source identification task (Mitchell, Johnson, \& Mather, 2003). Participants were given the Source Identification task, which is comprised of 32 statements that asked participants to decide if the items were seen in the video, appeared in the Source Identification Questionnaire, appeared in both the video and the Source Identification Questionnaire, or were not presented in either the video or the Source Identification Questionnaire. Participants were asked to indicate a response for each item but also to indicate if they were completely unsure/guessed. The statements were administered on a CD and were spaced 8 seconds apart.

\section{Procedure}

See Appendix A for outline of procedure. Participants were recruited via West Virginia University’s Research Participation System (SONA) and via in-class announcements and fliers. 


\section{Experimental procedures}

Four experimenters ( 3 females, 1 male) ran participants in this study. First, participants completed the Mood and Anxiety Symptom Questionnaire to measure trait anxiety and completed a demographics questionnaire. Participants were then given the infrequency validity items from the Zuckerman-Kuhlman Personality Questionnaire. Participants’ baseline mood was assessed using the Emotional Experiences Questionnaire. Immediately following completion of the Mood and Anxiety Symptom Questionnaire, the demographic questionnaire was reviewed by the researchers. Any participant who had previous treatment or was currently in treatment for anxiety was instantly placed in the mood stabilizing induction condition, regardless of the condition in which the remainder of the group was placed. During that time, participants were asked to take a break and remain in the back of the room.

Participants who were assigned to the high state anxiety groups were given an anxious mood induction via computer and participants who were assigned to the low state anxiety groups were given a mood stabilizing induction via computer. Participants completed a second mood assessment using the Emotional Experiences Questionnaire to be certain that the anxious and mood stabilizing inductions were effective. Participants were presented with to-be-source monitored information via two methods: (1) viewing a forensically relevant video and (2) responding to a questionnaire. Next, all participants were given a positive mood induction and filler tasks totaling 40 minutes. They then completed the Emotional Experiences Questionnaire for a final time to ensure that the effects of the anxious mood induction no longer impacted participants when they next participated in the source identification task. Finally, participants completed an eyewitness source identification task that required them to accurately report the source of previously provided forensically relevant information that was viewed in the video or 
that was presented in the Source Identification Questionnaire. Participants were then verbally debriefed and asked to not share details of this study with other undergraduate students. All participants received extra credit, if permitted by their course, for participation in this study. To encourage participation during a period of low registration numbers for summer classes, payment of $\$ 25$ was offered to nine participants in addition to the extra credit.

\section{Mood Manipulation Checks}

\section{Results}

Anxious mood induction condition. See Table 1. If the anxious mood induction was effective, a significant increase from Time 1 (baseline) to Time 2 (post anxious mood induction) would be expected. Therefore, a paired samples t-test using baseline and post-anxious mood induction ratings on the anxiety item on the Emotional Experiences Questionnaire was conducted. There was a statistically significant increase in anxiety ratings from Time 1 to Time 2, $t(35)=-10.33, p<.0005$ (two-tailed). Therefore, the anxious mood induction was effective. To determine whether anxiety decreased as a result of the positive mood induction and filler tasks, a paired-samples t-test was conducted on Time 2 to Time 3 (before the source identification task) anxiety Likert scale ratings on the Emotional Experiences Questionnaire. There was a statistically significant decrease in anxiety ratings from Time 2 to Time $3, t(35)=$ $10.11, p<.0005$ (two-tailed). The mean decrease in anxiety ratings was 2.97 with a $95 \%$ confidence interval ranging from 2.38 to 3.57. To determine how anxiety levels changed from Time 1 to Time 3, another paired-samples t-test was performed. Anxiety levels at Time 1 significantly differed from those at Time $3, t(35)=2.16, p=.04$. Anxiety decreased significantly as a result of the positive mood induction and filler tasks, so participants were no longer in a high state of anxiety when completing the source identification task. More specifically, participants were least anxious at the time of the source identification task. 
A paired-samples t-test was performed on Time 1 to Time 2 anxiety Likert scale ratings on the Emotional Experiences Questionnaire to ensure that participants' anxiety levels in the mood stabilizing induction condition did not increase following the induction. The anxiety ratings at Time 1 were statistically different from the anxiety ratings at Time $2, t(35)=3.71, p=$ .001 (two-tailed). The mean decrease in anxiety ratings was 1.03 with a $95 \%$ confidence interval ranging from .46 to 1.59. Participants were less anxious following the mood stabilizing induction.

Finally, a paired-samples t-test was also performed for anxiety levels from Time 2 to Time 3. The anxiety ratings at Time 2 were not statistically different from the anxiety ratings at Time 3, $t(35)=-.44, p=.66$ (two-tailed). The mean increase in anxiety ratings was .11 with a 95\% confidence interval ranging from -.62 to .40. Participants’ anxiety levels did not statistically change as a result of the mood stabilizing induction.

Mood stabilizing condition. If the mood stabilization induction was effective, a significant increase in anxiety from Time 1 (baseline) to Time 2 (post anxious mood induction) would not be expected. A paired-samples t-test was performed on Time 1 to Time 2 anxiety Likert scale ratings on the Emotional Experiences Questionnaire to ensure that participants’ anxiety levels in the mood stabilizing induction condition did not increase following the induction. The anxiety ratings at Time 1 were statistically different from the anxiety ratings at Time 2, $t(35)=3.71, p=.001$ (two-tailed). The mean decrease in anxiety ratings was 1.03 with a 95\% confidence interval ranging from .46 to 1.59. Participants were less anxious following the mood stabilizing induction.

Finally, a paired-samples t-test was also performed for anxiety levels from Time 2 to Time 3. The anxiety ratings at Time 2 were not statistically different from the anxiety ratings at 
Time 3, $t(35)=-.44, p=.66$ (two-tailed). The mean increase in anxiety ratings was .11 with a 95\% confidence interval ranging from -.62 to .40. Participants’ anxiety levels did not statistically change as a result of the mood stabilizing induction.

Of interest, baseline anxiety ratings on the Emotional Experiences Questionnaire significantly correlated with anxiety scores on the General Distress: Anxious Arousal scale on the Mood and Anxiety Symptom Questionnaire, $r=.24, p=.04$.

\section{State-Trait Anxiety Analyses}

See Table 2. To determine the effects of state and trait anxiety on performance on source identification, a 2 (High vs. Low Trait Anxiety) X 2 (High vs. Low State Anxiety) ANOVA was conducted with the number of correct source monitoring responses as the dependent variable.

There was a statistically significant main effect for state anxiety, $F(1,68)=6.02, p=$ .02 ; the effect size was moderate (partial eta squared $=.08$ ). High state anxiety increases accuracy on an eyewitness memory task. Participants who were in a high state of anxiety were more accurate on the source monitoring task than were those who were in a low state of anxiety. The main effect for trait anxiety, $F(1,68)=.37, p=.55$, did not reach statistical significance. In this study, clinically significant levels of anxiety did not influence eyewitness memory. The interaction effect between state and trait anxiety was not statistically significant, $F(1,68)=.38$, $p=.54$. 
Effects were also examined after removing participants' guesses on the source identification task. $^{1}$

See Table 3. To examine whether participants performed better on any particular type of question on the source identification task (questions about the video, the questionnaire, the video plus questionnaire, or new information), a two-way between-groups multivariate analysis of variance (MANOVA) was performed. Four dependent variables were used: to-be-remembered material from the video only, from both the video and the questionnaire, from neither the video nor the questionnaire (i.e., new information), and information from the questionnaire only. The independent variables were state and trait anxiety levels (high vs. low). There was not a statistically significant state- trait anxiety interaction effect, $F(4,65)=.91, p=.46$; Wilks’ Lambda $=.95$; partial eta squared $=.05$ nor was there a statistically significant difference between high and low trait anxiety, $F(4,65)=.57, p=.69$; Wilks’ Lambda $=.97$; partial eta squared $=.03$, on the combined dependent variables. However, there was a statistically significant difference between high and low state anxiety on the combined dependent variables, $F(4,65)=2.89, p=.03 ;$ Wilks’ Lambda $=.85 ;$ partial eta squared $=.15$.

${ }^{1}$ A 2 (High vs. Low Trait Anxiety) X 2 (High vs. Low State Anxiety) ANOVA was conducted with the number of correct source monitoring responses that were not guesses as the dependent variable. The interaction effect between state and trait anxiety was not statistically significant, $F(1,68)=.00, p=.97$. The main effect for state anxiety, $F(1,68)=3.54, p=.06$, became nonsignificant. The main effect for trait anxiety, $F(1,68)=.02, p=$ .90 , remained nonsignificant. This analysis was conducted because it was expected that source monitoring was not being measured if an individual did not have a memory for the event, or in other words, they guessed. However, these results suggest that participants were not accurate in determining if they were guessing. Therefore, these results should be interpreted with caution. 
When the results for the 4 dependent variables were considered separately, the only mean difference that reached statistical significance was the to-be-remembered material from the video only, $F(1,68)=10.01, p=.002$, partial eta squared $=.13$. Participants in a high state of anxiety more accurately remembered information that was only presented in the video than participants in a low state of anxiety. Surprisingly, there was no significant effect of anxiety on misleading information presented in the questionnaire which is inconsistent with the previous literature on anxiety and suggestibility.

\section{Discussion}

The current study examined the novel question of whether highly anxious people perform differently on an eyewitness memory task when they are in a high state of anxiety. In order to examine this question, this study employed a 2 (high vs. low state) X 2 (high vs. low trait) design using a source monitoring task as the outcome variable. In the current design, participants were anxious at encoding of the to-be-remembered event, but were not anxious during the eyewitness recall task. With a single exception, previous studies on anxiety and eyewitness memory have limited their designs to include manipulations of state anxiety only or measurement of existing trait anxiety. The one study that included measurement of state and trait anxiety, measured trait anxiety before the to-be-remembered event and state anxiety after the to-be-remembered event, and therefore addressed a different research question.

There was a main effect of state anxiety in the current study such that people who were in a high state of anxiety as a result of an anxious mood induction that was administered prior to viewing the to-be-remembered video made fewer errors on the source monitoring task. YerkesDodson's law (1908) theorizes that moderate levels of anxiety are ideal for cognitive performance. Levels of anxiety that are too low or too high impair performance. In the current 
study, anxiety was measured immediately following the anxious mood induction and levels were moderate. This moderate level of anxiety represented a statistically significant increase from a baseline rating that was taken immediately prior to the mood induction. This suggests that the anxious mood induction was effective. It is important to point out that participants were no longer anxious when they completed the source monitoring task as measured by another set of anxiety ratings given immediately prior to the source monitoring task. The anxious mood induction employed in the current study lasted for approximately 35 minutes (Sinclair et al., 1997). The source monitoring eyewitness task was completed approximately 40 minutes after the end of the anxious mood induction. Filler tasks and a positive mood induction were provided in the interim time period.

The current study failed to find that trait anxiety impacts eyewitness performance as there was no main effect of trait anxiety. That is, high levels of general anxiety similar to those of people with clinically significant anxiety did not influence eyewitness memory. Due to attentional biases associated with anxiety, it might be expected that an individual high in anxiety might perform better on an eyewitness task (e.g., Coles et al., 2007). Findings of other research suggest that people high in anxiety might perform better on an eyewitness task. However, performance was equivalent. The interaction between state and trait anxiety was also nonsignificant, and therefore the current study failed to find differences in the performance of highly anxious individuals in a current state of high anxiety. The nonsignificant findings may be a result of lack of power given that we only had 5 participants in this group. This group was hard to fill because for ethical reasons we nonrandomly assigned people who were high in anxiety who were currently in treatment for an anxiety disorder to the mood stabilizing condition. A second possible explanation is that the to-be-remembered video depicting the crime was not 
anxiety-provoking. Although the video depicted a robbery and high-speed chase, the video is nonviolent. Witnessing a crime generally increased an individual's anxiety level; however, it is likely that the video did not exert the same influence on the subjects in this study that would be expected if they witnessed a crime outside of the experimental setting. Therefore, one might assume that the five participants with clinically significant levels of anxiety who were in a high state of anxiety would experience a higher level of anxiety in response to the video. However, these 5 participants had a lower average anxiety score on the Emotional Experiences Questionnaire after video viewing $(M=3.20, S D=2.28)$ than did the 31 participants who had clinically significant anxiety levels, but who were in a high state of anxiety $(M=3.74, S D=$ 1.80).

A review of the literature finds that anxious individuals are not more likely than nonanxious individuals to get accurate information correct on source monitoring tasks, but that they are more likely to get more misleading responses correct. In the current study, participants were asked to either indicate whether information came from 4 categories: video only, questionnaire only, video plus questionnaire, or was new and therefore never presented. The information presented in the questionnaire is conceptualized as misleading information. Therefore, to examine whether the basic finding of greater eyewitness accuracy in the face of misleading information replicated in this study, we analyzed responses to the "questionnaire" questions. We did not find a significant main effect of state anxiety, trait anxiety, or a significant interaction. It is possible that presenting misinformation in a questionnaire instead of in an in-person interview did not lend itself to being impacted by anxiety.

Further analyses of responses from the video only, from the questionnaire only, or from both the video and the questionnaire were competed. Participants who received the anxious 
mood induction were more accurate in response to identifying source monitoring information presented in the video only than participants who received a neutral mood induction. This suggests that anxious participants better encoded the video than did the non-anxious participants. There were no significant effects of trait anxiety or significant interaction. This explanation is consistent with the Dobson and Markham (1992) findings that high state anxiety at encoding improves memory performance. Regarding the video plus the questionnaire and the new information, there were no significant main effects or interactions, but the pattern of means was in the expected direction with high state anxiety participants having means indicating slightly higher accuracy.

In general, the results of this study do not converge with previous findings in the memory literature which suggests that anxiety impairs memory performance (e.g., Kaye et al, 1953). Rather, these results converge more closely with previous findings in the suggestibility literature and in the memory literature in which potentially threatening information is presented showing that high anxiety is linked to reduced suggestibility or greater accuracy. In this study, high state anxiety was associated with fewer source monitoring errors. Although the findings of the current study directly replicate the findings of Ridley and Clifford (2006), who also found effects of high state anxiety but no effect of high trait anxiety and no significant interaction, the method does not allow for direct comparisons to be drawn. State anxiety was measured after the to-beremembered video.

A major strength of the current study is the fact that the anxious mood induction was not confounded with to-be-remembered material or the memory interview itself. Instead, state anxiety was manipulated prior to presentation of the to-be-remembered material and checks were used to determine the effectiveness of the anxious mood induction to ensure that participants 
were more anxious at the time of encoding rather than during any other time throughout the experiment. Additionally, the current study utilized the Mood and Anxiety Symptom Questionnaire, which is a measure of pure anxiety that is able to differentiate between depression and anxiety, unlike the commonly used State-Trait Anxiety Inventory which measures distress rather than anxiety.

A limitation to the study is the lack of practice items that would have allowed the researchers to screen for lack of understanding of the source monitoring task. Some participants performed at or below chance level on the source monitoring tasks and without those screening items, it is impossible to determine whether participants completely understood the task directions.

In sum, in this study, clinically significant levels of anxiety did not influence eyewitness memory. However, being anxious during encoding is associated with more accurate recall on a source monitoring task. In addition, clinically significant levels of anxiety do not interact with state anxiety to produce differences in source identification accuracy. 


\section{References}

Almerigogna, J., Ost, J., Bull, R., \& Akehurst, L. (2007). State of high anxiety: How nonsupportive interviewers can increase the suggestibility of child witnesses. Applied Cognitive Psychology, 21 (7), 963-974. doi: 10.1002/acp.1311

Barker, B. M., Barker, H. R., \& Wadsworth, A. P. (1977). Factor analysis of the items of the State-Trait Anxiety Inventory. Journal of Clinical Psychology, 33 (2), 450-455. doi: 10.1002/1097-4679(197704)33:2<450::AID-JCLP2270330225>3.0.CO;2-M

Beck, A. T., \& Emery, G. (1979).Cognitive therapy of anxiety and phobic disorders. Philadelphia: Center for Cognitive Therapy.

Becker, E. S., Roth, W. T., Andrich, W. T., \& Margraf, J. (1999). Explicit memory in anxiety disorders. Journal of Abnormal Psychology, 108 (1), 153-163. doi: 10.1037/0021843X.108.1.153

Buckby, J. A., Yung, A. R., Cosgrave, E. M., \& Killackey, E. J. (2007). Clinical utility of the Mood and Anxiety Symptom Questionnaire (MASQ) in a sample of young help-seekers. BMC Psychiatry, 7.doi: 10.1186/1471-244X-7-50

Chambers, K. L., \& Zaragoza, M. S. (2001). Intended and unintended effects of explicit warnings on eyewitness suggestibility: Evidence from source identification tests. Memory and Cognition, 29 (8), 1120-1129.

Clark, L. A., \& Watson, D. (1991). A tripartite model of anxiety and depression: Psychometric evidence and taxonomic implications. Journal of Abnormal Psychology, 100 (3), 316336.doi: 10.1037/0021-843X.100.3.316 
Coles, M. E., Turk, C. L., \& Heimberg, R. G. (2007). Memory bias for threat in generalized anxiety disorder: The potential importance of stimulus relevance. Cognitive Behaviour Therapy, 36 (2), 65-73. doi: 10.1080/16506070601070459

Dobson, M., \& Markham, R. (1992). Individual differences in anxiety level and eyewitness memory. The Journal of General Psychology, 119 (4), 343-350.

Eysenck, M. W., \& Calvo, M. G. (1992). Anxiety and performance: The processing efficiency theory. Cognition and Emotion, 6 (6), 409-434. doi: 10.1080/02699939208409696

Gudjonsson, G. H. (1988). Interrogative suggestibility: Its relationship with assertiveness, socialevaluative anxiety, state anxiety and method of coping. British Journal of Clinical Psychology, 27 (2), 159-166.

Johnson, M. K., Hashtroudi, S., \& Lindsay, D. S. (1993).Source monitoring.Psychological Bulletin, 114 (1), 3-28. doi: 10.1037/0033-2909.114.1.3

Josephson, B. R., Singer, J. A., \& Salovey, P. (1996). Mood regulation and memory: Repairing sad moods with happy memories. Cognition and Emotion, 10 (4), 437-444. doi: $10.1080 / 026999396380222$

Kaye, D., Kirschner, P., \& Mandler, G. (1953). The effect of test anxiety on memory span in a group test situation. Journal of Consulting and Clinical Psychology, 17 (4), 265-266. doi: 10.1037/h0054617

Kennedy, B. L., Schwab, J. L., Morris, R. L., \& Beldia, G. (2001). Assessment of state and trait anxiety in subjects with anxiety and depressive disorders. Psychiatric Quarterly, 72 (3), 263-276. doi: 10.1023/A:1010305200087 
Keogh, E., \& Reidy, J. (2000). Exploring the factor structure of the Mood and Anxiety Symptom Questionnaire (MASQ).Journal of Personality Assessment, 74 (1), 106-125. doi: 10.1207/S15327752JPA740108

McCabe, R. E. (1999). Implicit and explicit memory for threat words in high- and low-anxietysensitive participants. Cognitive Therapy and Research, 23 (1), 21-38. doi: 10.1023/A:1018706607051

Merckelbach, H., Muris, P., Wessel, I., \& van Koppen, P. J. (1998). The Gudjonsson Suggestibility Scale (GSS): Further data on its reliability, validity, and metacognition correlates. Social Behavior and Personality, 26 (2), 203-210. doi: 10.2224/sbp.1998.26.2.203

Mitchell, K. J. \& Zaragoza, M. S. (2001). Contextual overlap and eyewitness suggestibility. Memory and Cognition, 29 (4), 616-626.

O’Banion, K. \& Arkowitz, H. (1977). Social anxiety and selective memory for affective information about the self. Social Behavior and Personality, 5 (2), 321-328. doi: 10.2224/sbp.1977.5.2.321

Papay, J. P., Costello, R. J., Hedl, J. J., \& Spielberger, C. D. (1975). Effects of trait and state anxiety on the performance of elementary school children in traditional and individualized multiage classrooms. Journal of Educational Psychology, 67 (6), 840-846. doi: 10.1037/0022-0663.67.6.840

Pezdek, K., \& Roe, C. (1995).The effect of memory trace strength on suggestibility. Journal of Experimental Child Psychology, 60 (1), 116-128. doi: 10.1006/jecp.1995.1034 
Reidy, J., \& Keogh, E. (1997). Testing the discriminant and convergent validity of the Mood and Anxiety Symptoms Questionnaire using a British sample. Personality and Individual Differences, 23 (2), 337-344. doi: 10.1016/S0191-8869(97)00048-2

Reisberg, D., \& Heuer, F. (2007).The influence of emotion on memory in forensic settings. The handbook of eyewitness psychology, Vol I: Memory for events (pp. 81-116). Mahwah, NJ US: Lawrence Erlbaum Associates Publishers. Retrieved from PsycINFO database.

Ridley, A. M., Clifford, B. R., \& Keogh, E. (2002). The effects of state anxiety on the suggestibility and accuracy of child eyewitnesses. Applied Cognitive Psychology, 16 (5), 547-558. doi: 10.1002/acp.813

Ridley, A. M., \& Clifford, B. R. (2004). The effects of anxious mood induction on suggestibility to misleading post-event information. Applied Cognitive Psychology, 18 (2), 233-244. doi: 10.1002/acp.963

Ridley, A. M., \& Clifford, B. R. (2006). Suggestibility and state anxiety: How the two concepts relate in a source identification paradigm. Memory, 14 (1), 37-45. doi: $10.1080 / 09658210444000494$

Roisman, G. I., Fortuna, K., \& Holland, A. (2006). An experimental manipulation of retrospectively defined earned and continuous attachment security. Child Development, 77 (1), 59-71. doi: 10.1111/j.1467-8624.2006.00856.x

Sarason, S. B., \& Mandler, G. (1952). Some correlates of test anxiety. The Journal of Abnormal and Social Psychology, 47 (4), 810-817. doi: 10.1037/h0060009

Sinclair, R. C., Soldat, A. S., \& Ryan, C. A. (1997). Development and validation of Velten-like image-oriented anxiety and serenity mood inductions. Basic and Applied Social Psychology, 19 (2), 163-182. doi: 10.1207/s15324834basp1902 
Watson, D., Weber, K., Assenheimer, J. S., Clark, L. A., Strauss, M. E., \& McCormick, R. A. (1995a). Testing a tripartite model: I. Evaluating the convergent and discriminant validity of anxiety and depression symptom scales. Journal of Abnormal Psychology, 104 (1), 314. doi: 10.1037/0021-843X.104.1.3

Watson, D., Clark, L. A., Weber, K., Assenheimer, J. S., Strauss, M. E., \& McCormick, R. A. (1995b). Testing a tripartite model: II. Exploring the symptom structure of anxiety and depression in student, adult, and patient samples. Journal of Abnormal Psychology, 104, 15-25. doi: 10.1037/0021-843X.104.1.15

Wenzel, A., \& Holt, C. S. (2002).Memory bias against threat in social phobia. British Journal of Clinical Psychology, 41 (1), 73-79. doi: 10.1348/014466502163804

Wolfradt, U., \& Meyer, T. (1998). Interrogative suggestibility, anxiety and dissociation among anxious patients and normal controls. Personality and Individual Differences, 25 (3), 425-432. doi: 10.1016/S0191-8869(98)00023-3

Zaragoza, M. S., \& Lane, S. M. (1994). Source misattributions and the suggestibility of eyewitness memory. Journal of Experimental Psychology: Learning, Memory, and Cognition, 20 (4), 934-945. doi: 10.1037/0278-7393.20.4.934

Zuckerman, M. (2002) Zuckerman-Kuhlman personality questionnaire (ZKPQ): An alternative five-factorial model. In B. de Raad, \& M. Perugini (Eds.), Big Five Assessment. Ashland, OH: Hogrefe \& Huber Publishers (pp. 376-392). 
Table 1

Mean anxiety ratings on the Emotional Experiences Questionnaire across conditions and time Mood Induction Condition T1 T2 T3 Anxious $1.03(1.03)_{\mathrm{a}}$ $3.67(1.85)_{b}$ $.69(1.04)_{\mathrm{C}}$ Mood Stabilizing $2.25(2.18)$ $1.22(1.87)$ $1.33(2.16)$

Notes. $N=72$. Means within rows not sharing the same subscript are significantly different 
Table 2

Descriptive statistics for main and interaction effects on total correct source monitoring

\begin{tabular}{|c|c|c|c|c|}
\hline & \multirow[t]{3}{*}{ Mean } & \multirow[t]{3}{*}{$\mathrm{SE}$} & $95 \%$ & $\mathrm{CI}$ \\
\hline & & & Lower & Upper \\
\hline & & & Bound & Bound \\
\hline \multicolumn{5}{|c|}{ Main effects } \\
\hline Low Trait Anxiety & 16.99 & .61 & 15.77 & 18.20 \\
\hline High Trait Anxiety & 17.79 & 1.16 & 15.46 & 20.11 \\
\hline Low State Anxiety & 15.78 & .77 & 14.25 & 17.31 \\
\hline High State Anxiety & 19.00 & 1.07 & 16.87 & 21.12 \\
\hline \multicolumn{5}{|c|}{ Interaction effects } \\
\hline Low Trait, Low State Anxiety & 15.78 & .92 & 13.94 & 17.62 \\
\hline Low Trait, High State Anxiety & 18.19 & .79 & 16.61 & 19.78 \\
\hline High Trait, Low State Anxiety & 14.77 & 1.23 & 13.32 & 18.22 \\
\hline High Trait, High State Anxiety & 19.80 & 1.98 & 15.85 & 23.75 \\
\hline
\end{tabular}

Note. $N=72$. 
Table 3

Descriptive statistics for source monitoring question type

\begin{tabular}{llll}
\hline Mean & SE & 95\% CI \\
\cline { 3 - 4 } & & Lower & Upper \\
& & Bound & Bound \\
\hline
\end{tabular}

Main effects

Low Trait Anxiety

Video Only

Both Video and Questionnaire

New Information

Misleading Information

High Trait Anxiety

Video Only

Both Video and Questionnaire

New Information

Misleading Information

Low State Anxiety

Video Only
6.04

4.95

3.35

.14

3.08

3.62

2.65

.28

2.09

3.21

6.54

5.43

4.47

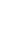


Both Video and Questionnaire

New Information

Misleading Information

High State Anxiety

Video Only

Both Video and Questionnaire

New Information

Misleading Information

\author{
High State Anxiety
}

4.68

.31

.17

2.82

3.50

3.16

2.58

.35

1.88

3.28

7.06

.44

6.19

7.93

4.98

.42

4.14

5.83

3.61

.24

3.13

4.08

Misleading Information

3.35

.49

2.37

4.33

\section{Interaction effects}

Low Trait, Low State Anxiety

Video Only

Both Video and Questionnaire

New Information

Misleading Information
5.57

4.74

3.09

2.39
.38

.37

.21

2.68

3.50

4.81

6.32

4.01

5.47

.42

1.55

3.24 
Low Trait, High State Anxiety

Video Only

Both Video and Questionnaire

New Information

Misleading Information

High Trait, Low State Anxiety

Video Only

Both Video and Questionnaire

New Information

Misleading Information

High Trait, High State Anxiety

Video Only

Both Video and Questionnaire

New Information

Misleading Information
6.52

.33

5.87

7.16

5.16

.32

4.53

5.79

3.61

.18

3.26

3.97

2.90

.37

2.17

3.63

.50

4.15

6.15

4.62

.49

3.64

5.59

3.23

.28

2.68

3.78

2.77

.56

1.64

3.90

Note. $N=72$.

7.60

.81

5.99

9.21

4.80

.79

3.23

6.37

3.60

.44

2.72

4.48

3.80

.91

1.99

5.62 


\section{APPENDIX A}

\section{Procedure}

1. Mood and Anxiety Symptom Questionnaire

2. Demographic Questionnaire

3. Infrequency Validity Items from the Zuckerman-Kuhlman Personality Questionnaire

4. Emotional Experiences Questionnaire

5. Anxious Mood Induction or Mood Stabilizing Induction

6. Emotional Experiences Questionnaire

7. To-be-source monitored information

8. Filler Task

9. Positive Mood Induction

10. Emotional Experiences Questionnaire

11. Source Identification Questionnaire 


\section{Kristina M. Kania, B.A.}

Updated 12/1/11

\begin{tabular}{ll}
\hline \multicolumn{1}{c}{ Office } & \multicolumn{1}{c}{ Home } \\
2228 Life Sciences Building & 5307 Scenic View Dr. \\
P.O. Box 6040 & Morgantown, WV 26508 \\
West Virginia University & (704)609-0326 \\
Morgantown, WV 26506 & kristinakania@gmail.com \\
(304)293-2001 & \\
kristina.kania@mail.wvu.edu & \\
\hline
\end{tabular}

\section{Education}

08/04-05/08 Bachelor of Arts, The University of North Carolina at Chapel Hill, Chapel Hill, NC.

Major: Psychology

02/07-07/07 Exchange Student, The University of New South Wales, Sydney, Australia.

\section{Current Position}

08/09 - present Graduate Student, West Virginia University, Department of Psychology, Morgantown, WV

APA Accredited Doctoral Program

Area of emphasis: Clinical Child Psychology

Advisor: Elisa Krackow, Ph.D.

\section{Clinical Experience}

$07 / 11-$ present

PsiMed Psychology Intern-West Virginia Industrial Home for Youth, Salem, WV.

Completing thorough psychological evaluations for placement and therapeutic services recommendations for adjudicated youth being evaluated; Completing psychological evaluations and leading group therapy for regularly committed adjudicated youth and adults, as well as evaluations for sex offender specific adjudicated youth and adults; Serving as member of multidisciplinary team to discuss recommendations for adjudicated youth; Administering and interpreting assessments, including the Kaufman Brief Intelligence Test-2, Minnesota Multiphasic Personality Inventory (MMPI)-Adolescent, MMPI-2, Estimate of Risk of Adolescent Sexual Offense Recidivism (ERASOR), and Juvenile Sex Offender 
$08 / 10-$ present

$08 / 09-08 / 11$

$11 / 10-03 / 11$

$07 / 08-08 / 09$

$07 / 08-08 / 09$
Assessment Protocol (JSOAP-II); Working with residents having a wide range of disorders, including Conduct Disorder, Antisocial Personality Disorder, Intermittent Explosive Disorder, Substance use disorders, and Mood disorders.

Supervisor: Thomas Horacek, Ph.D.

Graduate Student Clinician-Quin Curtis Center, West Virginia University, Morgantown, $W V$.

Conducting family therapy for a range of disorders, including Oppositional Defiant Disorder, Specific Phobia related to weather, Social Anxiety Disorder, Separation Anxiety Disorder, and Attention-Deficit/Hyperactivity Disorder; Utilizing Parent Child Interaction Therapy and other behavioral parent-training programs; Utilizing Cognitive-Behavioral Therapy to treat Dysthymia; Administering and interpreting the Behavior Assessment System for Children, 2nd Edition, the Eyberg Child Behavior Inventory, and the State-Trait Anxiety Inventory for Children. Supervisor: Christina Duncan, Ph.D.

\section{Graduate Student Clinician-Quin Curtis Center, West Virginia University,} Morgantown, $W V$.

Conducted individual therapy with an adult with Obsessive-Compulsive Disorder and provided behavioral parent-training to a family with a child with Oppositional Defiant Disorder, Attention-Deficit/Hyperactivity Disorder, and Social Anxiety Disorder; Administered and interpreted the Millon Clinical Multiaxial Inventory (MCMI)-III, the Parenting Stress Index, the Child Behavior Checklist, the Anxiety Disorders Interview Schedule-IV, the Spence Preschool Anxiety Scale, the Conners Rating Scale-Revised, and the Stanford-Binet Intelligence Scales, $5^{\text {th }}$ Edition. Supervisor: Elisa Krackow, Ph.D.

Graduate Student Clinician-Quin Curtis Center, West Virginia University, Morgantown, WV.

Utilized Cognitive-Behavioral Therapy for treating insomnia with an adult client; Administered and interpreted the Pittsburgh Sleep Quality Index, the Epworth Sleepiness Scale, the Insomnia Severity Index, the Beck Anxiety Inventory, and the Center for Epidemiological Studies Depression Scale.

Supervisor: Amy Fiske, Ph.D.

Psychiatric Technician-Behavioral Health Center, Carolinas Medical CenterRandolph, Child and Adolescent Partial Hospitalization, Charlotte, NC.

Co-facilitated group therapy, treatment planning groups, school activities, recreational therapy, and gender informational groups with children and adolescents, six to eighteen years of age in an outpatient setting; Oriented patients to unit; Monitored patients' behaviors throughout the day; Recorded daily behavioral observations for patients.

Supervisors: Alan Bozman, Ph.D., Kelly McCracken, M.S.W.

\section{Psychiatric Technician-Behavioral Health Center, Carolinas Medical Center-} Randolph, Psychiatric Emergency Department, Charlotte, NC.

Monitored all children, adolescents, and adults who presented to the psychiatric emergency department; Documented patients' behaviors; Assisted Registered Nurses and patients; Trained in Crisis Prevention Intervention (CPI) and in Cardiopulmonary Resuscitation (CPR).

Supervisor: Nicole McMillion, R.N. 
12/06 - 01/07 Psychology Intern-Behavioral Health Center, Carolinas Medical Center-

Randolph, Child and Adolescent Partial Hospitalization, Charlotte, NC.

Participated in group therapy, treatment planning groups, school activities, and recreational therapy with children and adolescents, six to eighteen years of age, in an outpatient setting.

Supervisors: Alan Bozman, Ph.D., Kelly McCracken, M.S.W.

\section{Manuscripts in Preparation}

\section{Scholarly Works}

Duncan, C., Dempsey, A., \& Kania, K. (manuscript in preparation). Pediatric and Adult Pulmonology. In C. Hunter, C. Hunter, \& R. Kessler (Eds.), Handbook of Clinical Psychology in Medical Settings: Evidence Based Assessment and Intervention.

Tien, K., Duncan, C., \& Kania, K. (manuscript in preparation). Caregiver factors related to unintentional burn injuries in young children.

Kania, K. \& Krackow, E. (manuscript in preparation). The impact of state and trait anxiety on performance in a source monitoring task.

\section{Conference Presentations}

Kania, K., Larson, N., Duncan, C., \& Simon, S. (2011, April). Managing pediatric asthma within the family: Responsibility, self-efficacy, and quality of life. Poster presentation at the Society for Pediatric Psychology conference, San Antonio, TX.

Krackow, E., Kania, K., Corman, L., \& Donley, S. (2011, March). The effects of negative and positive mood on recall of stressful life events. Poster presentation at the annual conference of American Psychology-Law Society, Miami, FL.

Ragatz, L., Fremouw, W., Schwartz, R., Anderson, R., \& Kania, K. (2010, March). Criminal tbinking, aggression, and psychopathy in late high school bully-victims. Poster presentation at the annual conference of American Psychology-Law Society, Vancouver, BC.

\section{Research Experience}

08/10 - present Pediatric Psychology Lab Member-West Virginia University, Department of Psychology, Morgantown, WV.

Co-authoring book chapter; Editing manuscripts; Co-reviewing manuscript for journal; Discussing and critiquing journal articles; Participating in didactic professional development seminars; Attending Cystic Fibrosis and Pediatric Psychology Grand Rounds at hospital, as well as attending Cystic Fibrosis Quality Improvement meetings; Attending and presenting at Pediatric Psychology conferences; Participating in lab group meetings.

Supervisor: Christina Duncan, Ph.D. 
08/09-present

$08 / 09-08 / 10$

$06 / 08-06 / 09$

$08 / 07-05 / 08$
Children's Cognition and Emotion Lab Member-West Virginia University, Department of Psychology, Morgantown, WV.

Conducting literature reviews; Preparing IRB proposals; Recruiting research participants; Training research assistants; Collecting data; Scoring and coding data; Entering data into SPSS files; Running statistical analyses; Discussing and critiquing journal articles; Attending and presenting at American Psychology-Law conferences; Participating in weekly/bi-weekly lab group meetings.

Supervisor: Elisa Krackow, Ph.D.

Graduate Research Assistant-West Virginia University, Department of Psychology, Morgantown WV.

Collected and coded data for studies with community and college samples that examined memory in preschool-aged children, the effects of positive and negative mood on recall of stressful life events, and the effects of negative mood induction on memory for negative life events.

Supervisor: Elisa Krackow, Ph.D.

Research Assistant-The University of North Carolina at Charlotte, Department of Psychology, Charlotte, NC.

Conducted literature searches; Participated in creation and distribution of forms for a study; Recruited and screened potential participants; Collected data at hospitals; Examined whether the hypothesized model of Posttraumatic Growth is applicable to children's experience in response to the trauma of diagnoses with Type 1

Diabetes.

Supervisor: Ryan Kilmer, Ph.D.

Research Assistant-The University of North Carolina at Chapel Hill, Department of Psychology, Chapel Hill, NC.

Examined children's memory for specific events using experimental design and hierarchically structured memory interview in two projects: In one study, tested effects of reminders on children's long-term recall of a novel event; In other study, focused on ways in which maternal instruction influences how mothers shape discussions about ongoing events and subsequently impact children's recall; Conducted literature searches; Collected data at preschools; Coded data. Supervisor: Peter Ornstein, Ph.D.

\section{Teaching Experience}

$08 / 10-05 / 11$

$11 / 10$
Graduate Instructor-West Virginia University, Morgantown, $W V$. Introduction to Psychology.

Lectured 3 hours a week for a pre-designed course; Supervised undergraduate teaching assistants (TA); Generated ideas, edited manuscript, and assisted with analyses for TA's Capstone project; Graded assignments; Proctored exams; Provided office hours for tutoring; Participated in weekly supervision meetings Supervisors: Constance Toffle, Ph.D., Julie Patrick, Ph.D.

Guest Lecturer-West Virginia University, Morgantown, $W V$. Psychology as a Profession.

Discussed and answered questions about working in the field of psychology with a Bachelor's degree.

Course Instructor: Cheryl McNeil, Ph.D. 


\section{Attended Workshops}

$11 / 10$

"Malpractice and Suicide"

Presenter: William Fremouw, Ph.D.

Location: West Virginia University.

Hours: 3

10/10 "Motivational Interviewing"

Presenters: Rochelle Cairns \& Dan McNeil, Ph.D.

Location: West Virginia University.

Hours: 7

$08 / 10$

"Assessing and Managing Suicide Risk: Core Competencies for University and College Mental Health Professionals" presented by the Suicide Prevention Resource Center.

Presenter: Glen A. Martin, Ph.D. from The University of North Carolina at Chapel Hill.

Location: Penn State University, Altoona, PA.

Hours: 8

\section{Editorial Experience}

Journal Co-Reviewer with Christina Duncan, Ph.D. for Journal of Pediatric Psychology

Conference Submissions Co-Reviewer with Elisa Krackow, Ph.D. for American

Psychology-Law Society

Conference Submissions Voluntary Reviewer for American Psychology-Law Society

\section{Memberships in Professional Organizations}

Association for Psychological Science (APS)

American Psychological Association (APA)_Graduate Student Affiliate

* Division 37 (Society for Child and Family Policy and Practice)

* Division 41 (American Psychology-Law Society)

* Division 53 (Clinical Child and Adolescent Psychology)

* Division 54 (Society of Pediatric Psychology)

* APAGS (American Psychological Association for Graduate Students) 


\section{Honors}

$\begin{array}{ll}\text { 05/07 - present } & \text { Psi Chi-The International Honor Society in Psychology } \\ \text { 05/07 - present } & \text { Sigma Alpha Lambda Honor Society } \\ 08 / 04-05 / 08 & \text { Dean's List (4 semesters) }\end{array}$

